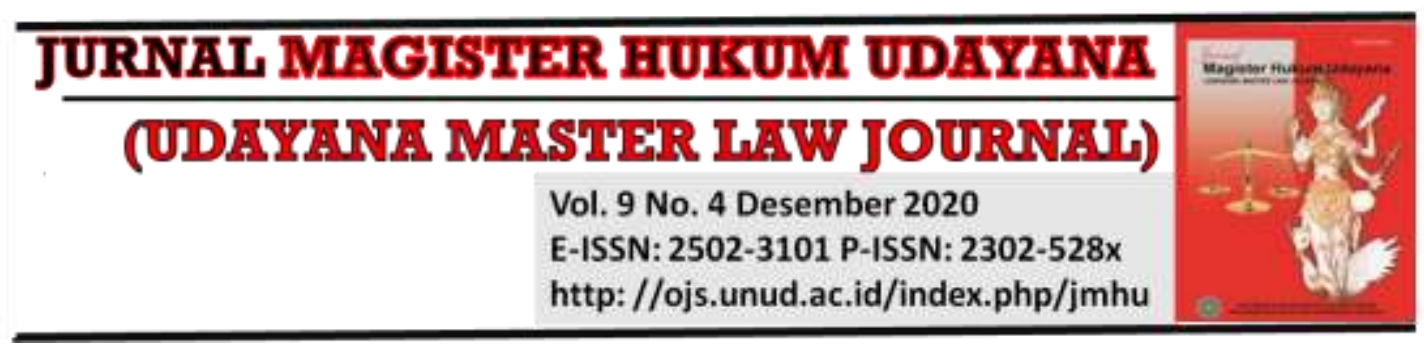

\title{
Investasi Cryptocurrency Berdasarkan Peraturan Bappebti No. 5 Tahun 2019
}

\author{
Dewa Ayu Fera Nitha1, I Ketut Westra²
}

${ }^{1}$ Kantor Hukum Bernad Vera Law Firm, E-mail: veranitha1402@gmail.com

${ }^{2}$ Fakultas Hukum Universitas Udayana, E-mail: ketutwestrafh@gmail.com

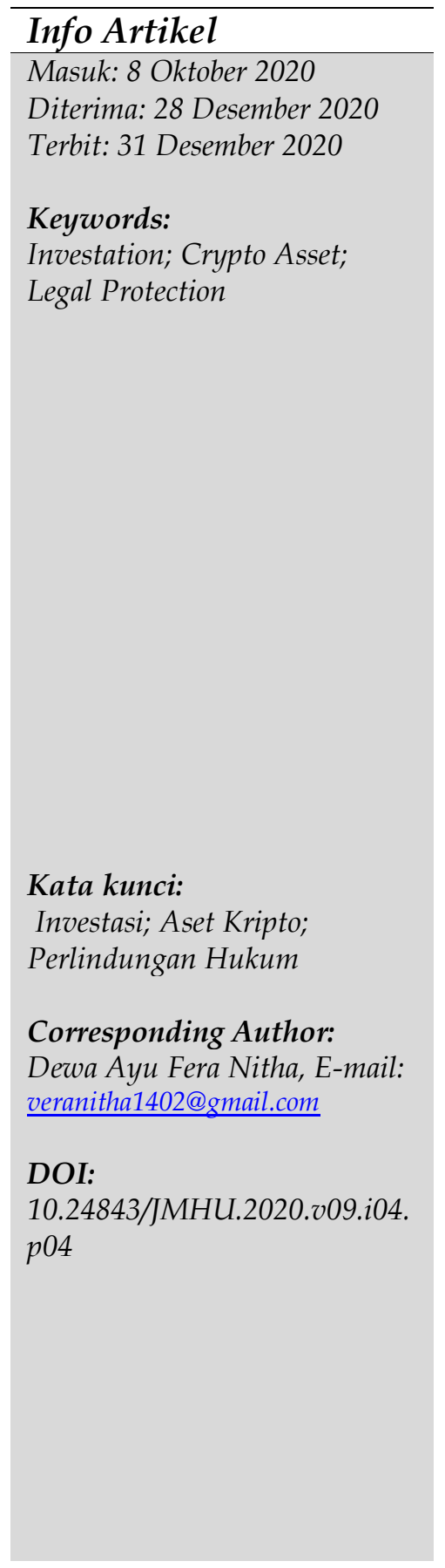

\begin{abstract}
Current technological developments have digital money or cryptocurrency which is currently being used as an investment by the world community. Seeing this, the government has now issued CoFTRA Regulation Number 5 of 2019 concerning Technical Provisions for the Implementation of the Physical Asset Market in the Futures Exchange to ensure legal protection for investors and legal certainty in the event of a dispute. This study aims to analyze protection The law against Cryptocurrency Investors is reviewed based on Bappebti Regulation Number 5 of 2019 and analyzes the legal efforts made in the event of a dispute in cryptocurrency investment. The research method in this study uses normative legal research methods with a statutory approach and a conceptual approach. The results of this study show that the Indonesian Government has accommodated the interests of crypto asset trading as well as a guideline and clarity for the public regarding the government's recognition of the presence of bitcoin and virtual currancy, namely through Bappebti Number 5 of 2019 and dispute disputes that occur between cryptocurrency investors and cryptocurrency marketplaces by way of non-litigation and arbitration through the Commodity Futures Trading Arbitration Board (BAKTI).

\section{Abstrak}

Perkembangan teknologi saat ini telah terdapat uang digital atau cryptocurrency yang saat ini dijadikan sebagai investasi oleh masyrakat dunia. Melihat hal tersebut kini pemerintah telah mengeluarkan Peraturan Bappebti Nomor 5 Tahun 2019 Tentang tentang Ketentuan Tekhnis Penyelenggaraan Pasar Fisik Asset Kripto (Crypto Asset) di Bursa Berjangka untuk memastikan adanya perlindungan hukum bagi para investor dan kepastian hukum apabila terdapat sengketa. Studi ini bertujuan untuk menganalisa perlindungan Hukum terhadap Para Investor Cryptocurrency dikaji berdasarkan Peraturan Bappebti Nomor 5 Tahun 2019 serta menganalisa upaya Hukum yang dilakukan apabila terjadi sengketa dalam investasi cryptocurrency. Metode penelitian dalam studi ini menggunakan metode penelitian hukum normatif dengan pendekatan perundang-undangan dan pendekatan konseptual. Hasil studi ini menunjukkan bahwa Pemerintah Indonesia telah mengakomodir kepentingan perdagangan kripto aset serta sebagai suatu pedoman dan kejelasan bagi masyarakat terkait pengakuan pemerintah terhadap kehadiran bitcoin dan virtual currancy yaitu melalui
\end{abstract}


Bappebti Nomor 5 Tahun 2019 dan perselisihan sengketa yang terjadi antara investor cryptocurrency dengan marketplace cryptocurrency dapat diselesaikan dengan jalan non-litigasi dan abitrase melalui Badan Arbitrase Perdagangan Berjangka Komoditi (BAKTI).

\section{Pendahuluan}

Indonesia merupakan negara yang tengah memasuki era 4.0. Era 4.0 merupakan era dimana teknologi berkembang sangat pesat sehingga mempengaruhi berbagai aspek kehidupan. Berbagai aspek kehidupan yang berpengaruh dalam perkembangan teknologi adalah aspek sosial, budaya, ekonomi dan bisnis. Selain itu, pesatnya perkembangan teknologi di dunia membuat semakin banyaknya penemuan baru yang diciptakan oleh para ahli untuk menemukan sesuatu yang baru setiap harinya. Para pembuat teknologi kemudian mulai menciptakan sesuatu yang tidak biasa yaitu dengan menciptakan alat bayar yang berbeda salah satunya dengan uang digital. Diciptakannya uang digital ini merupakan terobosan para penemu dalam bidang transaksi ekonomi bisnis. Keribetan dalam membawa uang cash dalam jumlah besar dan adanya faktor keamanan membuat adanya uang digital semakin dinikmati. Awalnya Bank Indonesia membagi 2 alat bayar di Indonesia secara tunai dan non tunai. Secara tunai dilakukan melalui uang cash, yang mana setoran secara tunai memiliki banyak kelemahan sehingga dibuatkanlah alat bayar non tunai yang penggunaanya semakin praktis dalam bentuk kartu, nota kredit, cek, bylet giro dan lainnya. Setelah berkembang dengan alat bayar non tunai kemudian berkembang menjadi uang digital. Semakin mendapat perhatian dari masyarakat dunia kemudian uang digital mulai digunakan sebagai investasi yang dinamakan cryptocurrency.

Cryptocurrency adalah sistem mata uang digital dimana pemakainya menggunakan pembayaran secara digital atas kegiatan bisnis yang dilakukan yang berfungsi sebagai mata uang standar. ${ }^{1}$ Cryptocurrency merupakan nama yang digunakan untuk suatu sistem dalam kriptografi, yang digunakan dalam proses pelepasan data secara aman dan untuk melakukan proses pergantian token digital secara tersebar. ${ }^{2}$ Cryptocurrency hadir untuk menjawab segala kendala-kendala yang terjadi dalam sistem penyetoran yang bergantung dari adanya pihak ketiga sebagai perusahaan pencetak adanya alat penyetoran uang elektronik. Kehadiran Cryptocurrency diawali dengan penemuan seperti halnya emas yang ditambang. Kemudian hasil emas yang ditambang ini dapat ditukar dalam bentuk uang konvensional dengan mata uang sesuai dengan negara dimana Cryptocurrency ditukarkan. Hasil tambang Cryptocurrency sering kali dipakai sebagai alat investasi layaknya saham dan emas, selain itu digunakan juga sebagai transaksi komersial elektronik seperti aplikasi game, aplikasi media social dan aplikasi lainnya. Sampai saat ini terdapat 1500 jenis mata uang Cryptocurrency, beberapa yang

${ }^{1}$ Syamsiah, N.O. (2017). Kajian Atas Cryptocurrency Sebagai Alat Pembayaran Di Indonesia. Indonesia Jornal on Networking And Security, DOI: http://dx.doi.org/10.2311/ijns.v6i1.1449. $\mathrm{h}$. 53-61.

2 Dourado, E., \& Brito, J. (2014). Cryptocurrency. The New Palgrave Dictionary of Economics. Online Edition. DOI: http://doi. org/10.1057/10.1057/9780230226203.3924. p.7. 
terkenal di masyarakat adalah etherum, ripple, litecoin, dogecoin, mrai, daschoin, dan yang paling terkenal dan popular saat ini adalah bitcoin. Cepatnya perkembangan mata uang digital Cryptocurrency, mulai menggetarkan pelayanan keuangan dan sistem pembayaran global saat ini, oleh karena berbeda dengan mata uang kertas yang tercetak.

Cryptocurrency dibuat melalui rumusan soal-soal matematika didasari kriptografi yang bersifat terdesentralisasi, yaitu jauh lebih aman dari pada yang sifatnya terpusat sehingga banyak masyarakat saat ini yang menjadikan Cryptocurrency sebagai investasi yang menjanjikan terutama di Negara berkembang salah satunya adalah Indonesia. cryptocurrency merupakan salah satu system gold eriging yang tidak terpengaruh oleh efektifitas politik domestik maupun internasional tentunya pemerintah berhak memanfaatkan pemberlakuan pajak yang sesuai bagi pengguna data bukan sebagai alat transaksi saja. ${ }^{3}$

Investasi atau penanaman modal didefinisikan sebagai bentuk transaksi atau perjanjian antara investor (pemilik modal) dengan investee (individu/perusahaan yang membutuhkan modal usaha). ${ }^{4}$ Dapat diartikan investasi merupakan transaksi bisnis yang dikerjakan oleh perorangan (natural person) ataupun badan hukum (juridical person) untuk usaha agar dapat memajukan dan mempertahankan nilai modal, baik dalam bentuk uang tunai (cash money), peralatan (equipment), asset tidak bergerak, haki, ataupun ketrampilan. ${ }^{5}$ Perkembangan Investasi di Indonesia tidak dapat dipungkiri, dipengaruhi oleh berbagai faktor salah satunya adalah faktor penting aturan hukum yang sangat dibutuhkan oleh para investor. ${ }^{6}$ Tingginya keuntungan yang didapat dari permainan saham investasi cryptocurrency di dunia membuat masyarakat Indonesia mulai tergiur untuk menginvestasikan sejumlah modalnya disana, bahkan kegiatan tersebut dilakukan secara illegal agar dapat memperoleh keuntungan dan investasi yang mengikuti perkembangan jaman saat ini. Banyaknya pelaku illegal dalam investasi cryptocurrency ini membuat pemerintah mulai membuat berbagai aturan agar pelaku investor cryptocurrency mendapat perlindungan agar nantinya investasi crytocurrency dapat diberlakukan legal di Indonesia. Kementerian Perdagangan selanjutnya disebut Kemendag melalui Badan Pengawas Perdagangan Berjangka Komoditas selanjutnya disebut Bappebti memberi kepastian hukum mengenai nasib Cryptocurrency di Indonesia dengan membentuk mekanisme pasar fisik asset kripto di bursa berjangka melalui beberapa peraturan. Dibuatnya beberapa aturan agar memberi ruang bagi investor untuk mengembangkan bisnis pembaharuan era komoditi digital, kepastian bisnis di sektor digital, adanya kepastian dan perlindungan hukum bagi para investor yang melakukan investasi di perdagangan asset kripto dan yang terpenting aturan itu juga menampilkan mengenai peraturan yang mengarah pada anti money laundering dan pembiayaan terorisme. Salah satu aturan yang digunakan dalam acuan investasi

3 Wibisono, M.G. (2020). Ketidakmampuan Indonesia Dalam Memanfaatkan Bitcoin dan Crytptocurrency, Transformasi Global. 6 (1).

${ }^{4}$ Simanjuntak.A. (2018). Hukum Bisnis Sebuah Pemahaman Integratif Antara Hukum Dan Praktik Bisnis. Depok: PT RajaGrafindo Persada. h. 112.

${ }^{5}$ Rahman, A.dan Suratman. (2019). Hukum Investasi \& Pasar Modal. Jakarta: Sinar Grafika. h. 3.

${ }^{6}$ Jumiadi, D.A.A.N.J. dan Markeling, I.K. (2018). Perlindungan Hukum Kegiatan Investasi Menggunakan Virtual Currency di Indonesia. Kerta Semaya. 4 (3). DOI: https://ojs.unud.ac.id/index.php/kerthasemaya/article/view/44077. h.7. 
cryptocurrency saat ini Peraturan Bappebti Nomor 5 Tahun 2019 Tentang Ketentuan Tekhnis Penyelenggaraan Pasar Fisik Asset Kripto (Crypto Asset) di Bursa Berjangka.

Dikeluarkannya aturan mengenai cryptocurrency tidak menjamin dapat memberikan perlindungan hukum bagi investor, oleh karena belum diaturnya aspek perlindungan hukum secara khusus apabila perusahaan cryptocurrency mengalami kerugian. Hal ini lah yang membuat adanya kekosongan hukum dalam aturan mengenai investasi cryptocurrency. Berdasarkan dari latar belakang yang telah disampaikan, adapun rumusan masalah yang dikaji dalam penulisan ini adalah Bagaimanakah Perlindungan Hukum terhadap Para Investor Cryptocurrency dikaji berdasarkan Peraturan Bappebti Nomor 5 Tahun 2019? Dan bagaimana upaya Hukum yang dilakukan apabila terjadi sengketa dalam investasi cryptocurrency?

Topik yang dibahas dalam jurnal ini masih bersifat original, oleh karena tidak ditemukan pada jurnal lain yang secara khusus mengenai investasi cryptocurrency setelah dikeluarkannya Peraturan Bappebti Nomor 5 Tahun 2019. Beberapa jurnal yang dapat dibandingkan dengan tulisan ini yaitu penelitian oleh Koeswanto E. S dan Taufik M pada tahun 2017 mengenai Perlindungan Hukum Terhadap Investor yang melakukan Investasi Virtual Currency dengan fokus kajian membahas mengenai peraturan tertulis terkait peredaran dan pengawasan serta formulasi kebijakan dan aspek perlindungan terhadap pengguna investasi virtual currency. ${ }^{7}$ Nassir, M. N. M, et. al pada tahun 2020 membahas mengenai Daya Tarik Cryptocurrency dengan fokus bahasan mengenai resiko dibalik penggunaan mata uang digital serta manfaatnya. ${ }^{8}$ Nurailati, A dan Azwari, P. C pada tahun 2018 mengkaji mengenai Akuntansi Untuk Cryptocurrency dengan fokus bahasan mengenai keabsahan penggunaan cryptocurrency sebagai mata uang dan alat pembayaran. ${ }^{9}$

Perbedaan antara jurnal ini dengan jurnal diatas adalah jurnal ini lebih membahas mengenai perlindungan hukum bagi investasi cryptocurrency serta penyelesaian sengketa akibat timbulnya perselisihan setelah berlakunya Peraturan Bappebti. Tujuan dalam studi ini adalah untuk menganalisa perlindungan Hukum terhadap Para Investor Cryptocurrency dikaji berdasarkan Peraturan Bappebti Nomor 5 Tahun 2019 serta menganalisa upaya Hukum yang dilakukan apabila terjadi sengketa dalam investasi cryptocurrency.

\section{Metode Penelitian}

Penulisan jurnal ini digunakan dengan metode penelitian hukum normatif. Pendekatan yang digunakan dalam penelitian ini adalah pendekatan perundang-undangan dan pendekatan konseptual dilakukan dengan cara yuridis normatif dengan berdasarkan pada peraturan perundang-undangan, salah satunya Peraturan Bappebti No.5 Tahun

\footnotetext{
${ }^{7}$ Koeswanto, E.S. dan Taufik.M (2017). Perlindungan Hukum Terhadap Investor Yang Melakukan Investasi Virtual Currency. Bogor: Program Magister Ilmu Hukum, Sekolah Pascasarjana Unversitas Djuanda, Jurnal Living Law, 9 (1). h.213.

8 Nassir, M.N.M., Seputro.E.P.dan Setyaningrum.D.P.(2020). Proceeding of The Urecol. p. 233237.

${ }^{9}$ Nurailati, A., dan Azwari, P.C. (2018). Akuntansi Untuk Cryptocurrency.I-Finance; A Research Journal On Islamic Finance; 4 (2), DOI: https://doi.org/10.19109/ifinance.v4i2.2885.
} 
2019 tentang Ketentuan Teknis Penyelenggaraan Pasar Fisik Aset Kripto (Crypto Asset). Menurut pemikiran Peter Mahmud Marzuki, penelitian hukum normatif merupakan suatu proses yang bertujuan untuk menemukan aturan hukum, prinsip hukum, maupun doktrin hukum dalam upaya menjawab permasalahan hukum yang sedang terjadi. ${ }^{10}$ Penelitian normatif pada dasarnya bersumber dari sumber hukum hukum primer dan sekunder, yang berasal dari aturan Undang-undang dan literature.

\section{Hasil dan Pembahasan}

\subsection{Perlindungan Hukum Terhadap Investasi Cryptocurrency Dikaji dari Peraturan Bappebti Nomor 5 Tahun 2019}

Merujuk pada pendapat Satjipto Raharjo, perlindungan hukum dapat diartikan sebagai semua hak yang diperoleh dari hukum dengan mengedepankan perlindungan untuk setiap hak asasi manusia yang merasa dirugikan oleh pihak lain ${ }^{11}$. Menurut pemikiran Muschin, perlindungan hukum berarti tindakan yang ditujukan sebagai perlindungan untuk setiap individu dengan menyerasikan ikatan nilai dan kaidah yang timbul disetiap prilaku dan tindakan untuk terwujudnya ketertiban dalam pergaulan hidup antar sesama manusia. ${ }^{12}$ Untuk mencegah adanya investor yang dirugikan, pemerintah mulai membuat suatu aturan agar nantinya para investor yang melakukan transaksi bisnis menjadi aman di dalam menjalankan bisnisnya. Dahulu investasi maupun transaksi cryptocurrency di Indonesia masih dilakukan secara tersembunyi atau illegal dengan adanya aturan dari Bappebti ini diharapkan dapat memberikan kepastian dan perlindungan hukum bagi investor, transaksi cryptocurrency di Indonesia. Adanya perlindungan hukum yang diberikan dapat meminilisir adanya kerugian, sengketa dan tindak pidana dalam investasi cryptocurrency. Maraknya investasi bodong yang menjanjikan untung besar untuk menarik calon investor membuat pemerintah terus berusaha untuk memperbaharui aturan hukum yang ada.

Pada perkembangan mileneal saat ini investasi cryptocurrency mulai menjadi tren anak muda dikalangan para pemain saham untuk memperoleh keuntungan yang tinggi. Pemain industry saham berpendapat cryptocurrency seperti bitcoin merupakan teknologi yang masih baru sehingga gampang menarik seorang milineal untuk menjadi tertarik apalagi untuk kalangan anak muda pemain saham yang ingin mendapatkan keuntungan lebih dan dengan cara yang lebih mudah. Para pemain saham di Indonesia lebih tertarik dengan sesuatu yang baru hal ini menjadikan investasi cryptocurrency lebih gampang untuk masuk ke Indonesia. Indonesia sudah mempunyai beberapa marketplace asing untuk perdagangan cryptocurrency salah satunya berasal dari Korea Selatan yaitu Upbit dan GoPax. Tingginya daya beli masyarakat Indonesia akan sesuatu yang baru membuat banyak marketplace asing berbondong-bondong untuk melakukan transaksi bisnis di Indonesia. Investasi cryptocurrency masih memiliki transmisi pengaruh krisis yang sangat panjang bahkan masih jauh, diantara indikasinya kapitalis pasar dari

${ }^{10}$ Fajar, M \& Achmad, Y. (2015). Dualisme Penelitian Hukum Normatif \& Empiris. Yogyakarta: Pustaka Pelajar. h. 90.

11 Satjipto, R. (2012). Ilmu Hukum. Bandung. Citra Aditya Bakti. h. 53.

12 Saputri, D. M. (2020). Perlindungan Hukum Terhadap Pembeli lelang Dalam Pelaksanaan Lelang Eksekusi Hak Tanggungan. Pamulang Law Review, 2(1), 7-12. DOI: http://dx.doi.org/10.32493/palrev.v2i1.5340. h. 20. 
cryptocurrency sangat kecil dibandingkan indeks saham seperti Jakarta Composite Index (JCI), South Korea Stock Exchange (KRX), dan Tokyo Stock Exchange (JLX). ${ }^{13}$

Terdahulu pengaturan mengenai alat pembayar yang sah di Indonesia diatur berdasarkan Undang-Undang Nomor 7 Tahun 2011 tentang Mata Uang (selanjutnya "UU Mata Uang"). Merujuk pada ketentuan dalam Pasal 1 angka 2 UU Mata Uang ditentukan bahwa "Uang adalah alat pembayaran yang sah". UU Mata Uang juga secara tegas menentukan bahwa mata uang yang dikeluarkan oleh Indonesia adalah Rupiah sebagaimana ditentukan dalam ketentuan Pasal 1 angka 1 UU Mata Uang. Merujuk pada ketentuan dalam Pasal 21 ayat (1) UU Mata Uang, Rupiah wajib digunakan dalam setiap transaksi yang mempunyai tujuan pembayaran, penyelesaian kewajiban lainnya yang harus dipenuhi dengan uang, dan/atau transaksi keuangan lainnya yang dilakukan di wilayah Negara Kesatuan Republik Indonesia. Bank Indonesia bahkan sempat menyatakan bahwa bitcoin dan virtual currency lainnya bukan merupakan mata uang atau alat pembayaran yang sah di Indonesia sebagaimana disampaikan dalam Pernyataan Bank Indonesia dalam Siaran Pers Bank Indonesia No. 16/6/Dkom dengan judul "Pernyataan Bank Indonesia Terkait Bitcoin dan Virtual Currency lainnya". ${ }^{14}$ Dalam pernyataan tersebut, pihak Bank Indonesia bahkan menegaskan bahwa segala risiko yang timbul atas penggunaan bitcoin dan virtual currency lainnya menjadi tanggung jawab pengguna bitcoin dan Pemerintah Indonesia tidak bertanggung jawab atas risiko yang mungkin terjadi dan dialami oleh pengguna. ${ }^{15}$

Seiring dengan perkembangannya, Indonesia kemudian mengatur mengenai cryptocurrency sebagai komoditi atau jual beli aset kripto. ${ }^{16}$ Pemerintah Indonesia kemudian menyusun beberapa aturan untuk mengakomodir kepentingan perdagangan kripto aset serta sebagai suatu pedoman dan kejelasan bagi masyarakat terkait pengakuan pemerintah terhadap kehadiran bitcoin dan virtual currancy yaitu melalui kebijakan Menteri Perdagangan Republik Indonesia Nomor 99 Tahun 2019 tentang Kebijakan Umum Penyelenggaraan Perdagangan Berjangka Aset Kripto yang pada intinya mengatur bahwa "Aset Kripto (crypto asset) ditetapkan sebagai Komoditi yang dapat dijadikan Subjek Kontrak Berjangka yang diperdagangkan di Bursa Berjangka", sebagaimana ditentukan dalam Pasal $1 .{ }^{17}$ Pengaturan lebih lanjut juga diatur oleh Badan Pengawas Perdagangan Berjangka Komoditi dalam aturan Bappebti Nomor 3 Tahun 2019 dan Bappebti Nomor 5 Tahun 2019.18

Dikaji dari aturan Bappebti Nomor 5 Tahun 2019 Tentang Ketentuan Teknis Penyelenggaraan Pasar Fisik Aset Kripto (Crypto Asset) Di Bursa Berjangka, untuk menjamin kepastian dan perlindungan hukum bagi investor cryptocurrency, wujud dari

${ }^{13}$ Saputra, E. (2018). Dampak Cryptocurrency Terhadap Perekonomian Indonesia. In Seminar Nasional Royal (SENAR) 1(1). h. 491-496.

14 Yohandi, A., Trihastuti, N., \& Hartono, D. (2017). Implikasi yuridis penggunaan mata uang virtual bitcoin sebagai alat pembayaran dalam transaksi komersial (studi komparasi antara Indonesia-Singapura). Diponegoro Law Journal, 6(2). h. 1-19.

${ }^{15} \mathrm{Ibid}$.

${ }^{16}$ Puspasari, S. (2020). Perlindungan Hukum bagi Investor pada Transaksi Aset Kripto dalam Bursa Berjangka Komoditi. Jurist-Diction, 3(1). h. 303-330.

17 Watung, P. (2020). Kajian Yuridis Mengenai Keberadaan Bitcoin Dalam Lingkup Transaksi Di Indonesia Ditinjau Dari UU No. 7 Tahun 2011 Tentang Mata Uang. Lex Et Societatis, 7(10).

18 Ibid. 
perlindungan hukum untuk investor cryptocurrency semua marketplace cryptocurrency harus memenuhi seluruh syarat yang telah diatur dalam aturan Bappebti dengan mengumpulkan semua file yang diminta, mengedepankan prinsip pengelolaan usaha yang benar seperti mengutamakan hak anggota bursa berjangka untuk memperoleh nilai yang terbuka dan menjamin konsumen tetap terlindungi agar dapat mencegah adanya money laundering (Pencucian Uang) dan pembiayaan terorisme serta proliferasi senjata pemusnah massal"19. Adapaun besar biaya capital minimum yang harus dimiliki oleh pedagang asse crypto harus mempunyai modal yang harus diberikan minimal Rp 1.500.000.000.000,00 (satu triliun lima ratus miliar rupiah) dengan saldo yang harus dipertahankan sebagai modal akhir minimal Rp 1.200.000.000.000,00 (satu triliun dua ratus miliar rupiah) dan Mempunyai minimal 3 (tiga) staff yang bersetifikasi centified information systems security professional (CISSP). Bappebti tidak hanya mengatur mengenai marketplace yang ingin menjadi platform cryptocurrency di Indonesia tetapi juga mengatur mengenai para investor yang ingin melakukan transaksi jual beli cryptocurrency dimana syarat yang harus dipenuhi yaitu investor didahulukan menempati uang yang akan digunakan untuk kegiatan transaksi dengan rekening yang terpisah atas nama marketplace yang dituju untuk kepentingan Lembaga Kliring Berjangka. Investor cryptocurrency hanya dapat menjual Asset Krypto apabila investor memiliki saldo marketplace crypto. Apabila terdapat pelanggaran yang dilakukan oleh marketplace crypto, maka bisa diberikan sanksi pembatalan persetujuan. Dengan batalnya persetujuan tersebut, maka marketplace Asset crypto wajib mengembalikan dana ataupun menyerahkan Asset crypto milik Konsumen Asset crypto yang dikelolanya, dan dilarang menerima konsumen Asset crypto yang baru. Selain dari aturan Bappebti, UU No.11 Tahun 2008 Tentang Informasi dan Transaksi Elektronik juga memberikan perlindungan hukum yakni pada pasal 9 yang menentukan bahwa "setiap pelaku usaha yang menawarkan produk melalui system elektronik harus menyediakan informasi yang lengkap dan benar berkaitan dengan syarat kontrak, produsen, dan produk yang ditawarkan" ${ }^{20}$

Pengaturan mengenai cryptocurrency ini sesuai dengan teori neo-classical economic theory yang pada intinya mengemukakan bahwa investasi memiliki kontribusi positif terhadap pembangunan ekonomi host-country. ${ }^{21}$ Merujuk pada pemikiran Sheriff H. Seid terdapat beberapa faktor yang dapat mendukung kontribusi positif investasi terhadap pembangunan ekonomi host-country seperti investor asing yang membawa modal ke host-country yang mempengaruhi kualitas dan kuantitas di negara tersebut; aliran modal dan investasi kembali keuntungan, mendorong peningkatan total saving di host-country, serta pendapat pemerintah yang meningkat melalui pajak dan pembayaran. Hal senada juga diungkapkan Sornarajah yang menyatakan bahwa investasi asing secara keseluruhan bermanfaat atau menguntngkan bagi host-country sehingga mampu mendorong pertumbuhan ekonomi dan pembangunan nasional.

Dengan adanya ketentuan-ketentuan yang tertuang dalam peraturan tersebut, maka investor cryptocurrency dapat menjamin investasinya akan aman, oleh karena marketplace

${ }^{19}$ Faisal, G. (2019). Legalitas Bitcoin Menurut Hukum Investasi Di Indonesia. (Doctoral Dissertation, Universitas Pasundan).

${ }^{20}$ Puspasari, S. (2020). Perlindungan Hukum bagi Investor pada Transaksi Aset Kripto dalam Bursa Berjangka Komoditi. Jurist-Diction, 3(1), 303-330. DOI: 10.20473/jd.v3il.17638, h.319.

${ }^{21}$ Zaidun, M. (2008). Paradigma Baru Kebijakan Hukum Investasi Indonesia Suatu Tantangan Dan Harapan. 
asset crypto sebagai pedagang asset kripto telah terlebih dahulu menjamin dananya, sehingga pedagang asset kripto tidak dapat dengan mudahnya menipu para investor cryptocurrency yang telah menanamkan modalnya. Para investor bisa menjamin keselamatan dan kepastian hukum dari kontrak yang dibuat. Legalitas cryptocurrency di Indonesia juga dapat membawa dampak positif dibidang investasi berkaitan dengan pembangunan ekonomi.

\subsection{Upaya Hukum Yang Dilakukan Apabila Terjadi Sengketa Dalam Investasi Cryptocurrency}

Upaya hukum merupakan upaya yang dilakukan untuk memperoleh perlindungan hukum yang merupakan hak bagi setiap individu. Upaya untuk mendapatkan perlindungan hukum tentunya yang diinginkan oleh manusia adalah ketertiban dan keteraturan antara nilai dasar dari hukum yakni adanya kepastian hukum, kegunaan hukum serta keadilan hukum. Perlindungan Hukum menurut C.S.T Kansil adalah penyempitan arti dari perlindungan, dalam hal ini hanya perlindungan oleh hukum saja. Perlindungan yang diberikan oleh hukum, terkait pula dengan adanya hak dan kewajiban, dalam hal ini yang dimiliki oleh manusia sebagai subyek hukum dalam interaksinya dengan hukum manusia serta lingkungannya. ${ }^{22}$ Selanjutnya, menurut pendapat dari Soetino, perlindungan hukum adalah adanya upaya melindungi masyarakat dari perbuatan sewenang-wenang penguasa yang tidak sesuai dengan aturan hukum, untuk mewujudkan ketertiban dan ketentraman sehingga memungkinkan manusia untuk menikmati martabatnya sebagai manusia. Perlindungan hukum merupakan suatu hal yang melindungi subjek-subjek hukum melalui peraturan perundang-undangan yang berlaku dan dipaksakan pelaksanaannya dengan suatu sanksi.

Diaturnya aturan mengenai investasi cryptocurrency di dalam Bappebti tidak menjamin bahwa suatu saat nanti tidak ada sengketa yang terjadi antara para investor cryptocurrency dengan marketplace cryptocurrency. Penyelesaian sengketa dalam aturan Bappebti telah diatur didalam peraturan Bappebti, dimana penyelesaian tetap diutamakan melalui musyawarah mufakat yaitu dengan jalan kekeluargaan.

Salah satu penyelesaian sengketa melalui jalur non-litigasi adalah Arbitrase. Berdasarkan UU Nomor 30 Tahun 1999 Tentang Arbitrase dan Alternatif Penyelesaian Sengketa Pasal 1 Angka 1 disebutkan "Arbitrase adalah cara penyelesaian suatu sengketa perdata diluar pengadilan umum yang didasarkan pada perjanjian arbitrase yang dibuat secara tertulis oleh para pihak yang bersengketa. Apabila tidak tercapai mufakat, para pihak dalam Perdagangan transaksi Fisik Asset criypto yang berselisih dapat menyelesaikan melalui wadah yang telah disediakan oleh Bursa Berjangka melalui Badan Arbitrase Perdagangan Berjangka Komoditi (BAKTI). BAKTI mengkhususkan diri pada sengketa perdata yang berhubungan dengan Perdagangan Berjangka Komoditi, Sistem Resi Gudang dan/atau transaksi-transaksi lain yang diatur

22 Kurniati, G. (2017). Akibat Hukum Pelanggaran Prosedur Pengadaan Barang/Jasa Pemerintah dan Perlindungan Hukum terhadap Organisasi Pengadaan Barang/Jasa Pemerintah. Jurnal Hukum POSITUM, 1(2), 311-327. DOI https://doi.org/10.35706/positum.v1i2.854, h. 321. 
dalam Bappetpti. ${ }^{23}$ Upaya hukum litigasi akan dilakukan apabila penyelesaian masalah melalui jalan mediasi dan BAKTI tidak tercapai, para pihak juga dapat memilih penyelesaian sengketa melalui Badan Penyelesaian Sengketa Konsumen (selanjutnya BPSK) sebagaimana ditentukan dalam ketentuan Pasal 52 Undang-Undang Nomor 8 Tahun 1999 tentang Perlindungan Konsumen bahwa BPSK memiliki kewenangan untuk melaksanakan penanganan dan penyelesaian sengketa konsumen, dengan cara melalui mediasi atau arbitrase atau konsiliasi. ${ }^{24}$ Berkaitan dengan perlindungan hukum terhadap kerugian yang dialami oleh investor sebagai konsumen dalam transaksi aset kripto yang dilakukan dengan mengandung unsur penupuan oleh pelaku usaha yang menjual aset kripto, maka investo dapat mengajukan gugatan penyelesaian sengketa kepada BPSK dimana putusan BPSK bersifat final dan mengikat. ${ }^{25}$

Apabila nantinya terdapat adanya unsur tindak pidana dalam investasi cryptocurrency, para pelaku usaha atau konsumen dan investor cryptocurrency dapat melaporkan tindak pidana tersebut ke pihak yang berwajib dengan memberlakukan UU No 19 tahun 2016 tentang ITE yang merupakan perbaikan dari UU No 11 tahun 2008 tentang ITE dalam menjerat pelaku yang telah melakukan tindak pidana tersebut. Undang-Undang ITE yang baru ini, merupakan peran pemerintah dalam melakukan pencegahan penyebarluasan dan penggunaan Informasi Elektronik dan/atau Dokumen Elektronik yang memiliki muatan yang dilarang dan melanggar hukum ${ }^{26}$.

\section{Kesimpulan}

Berdasarkan pembahasan tersebut diatas dapat disimpulkan bahwa Pemerintah Indonesia kemudian menyusun beberapa aturan untuk mengakomodir kepentingan perdagangan kripto aset serta sebagai suatu pedoman dan kejelasan bagi masyarakat terkait pengakuan pemerintah terhadap kehadiran bitcoin dan virtual currancy yaitu melalui kebijakan Menteri Perdagangan Republik Indonesia Nomor 99 Tahun 2019. Pengaturan lebih lanjut juga diatur oleh Badan Pengawas Perdagangan Berjangka Komoditi dalam aturan Bappebti Nomor 3 Tahun 2019 dan Bappebti Nomor 5 Tahun 2019. Dengan adanya aturan Bappebti maka marketplace yang akan melakukan perdagangan cryptocurrency dananya dijamin terlebih dahulu sehingga nantinya akan meminimalkan adanya tindak pidana penipuan yang dilakukan oleh marketplace cryptocurrency. Adanya perselisihan sengketa yang terjadi antara investor cryptocurrency dengan marketplace cryptocurrency dapat diselesaikan dengan jalan non-litigasi dan abitrase melalui BAKTI. Selain itu, penyelesaian sengketa juga dapat dilakukan oleh para pelaku transaksi cryptocurrency melalui BPSK.

\section{Ucapan terima Kasih (Acknowledgments)}

Ucapan terima kasih ditujukan untuk seluruh pihak yang berkontribusi dalam penelitian ini, Terutama kepada Universitas Udayana sebagai tempat peneliti

${ }^{23}$ Peraturan Badan Arbitrase Perdagangan Berjangka Nomor Per-01/BAKTI/01.2009 Tentang Peraturan Dan Cara Arbitrase.

${ }^{24}$ Puspasari, S. loc. cit.

${ }^{25} \mathrm{Ibid}$.

${ }^{26}$ Tampi, M.M. (2017). Legal Protection for Bitcoin Investors In Indonesia: To Move Beyond The Current Exchange System. Jurnal Hukum \& Pembangunan, 47 (1). h. 83-99. 
menempuh pendidikan. Kepada para dosen Pengempu mata kuliah di Magister Hukum serta pembimbing agar penelitian ini bisa diselesaikan dengan baik dan benar. Selain itu ucapan terima kasih ditujukan kepada teman-teman peneliti yang selalu bersedia semangat dan dukungan.

\section{Daftar Pustaka}

\section{$\underline{\text { Buku }}$}

Fajar, M \& Achmad, Y. (2015). Dualisme Penelitian Hukum Normatif \& Empiris, Yogyakarta: Pustaka Pelajar.

Satjipto, R. (2012). Ilmu Hukum. Bandung. Citra Aditya Bakti.

Simanjuntak.A. (2018). Hukum Bisnis Sebuah Pemahaman Integratif Antara Hukum Dan Praktik Bisnis. Depok: PT RajaGrafindo Persada.

Rahman, A.dan Suratman. (2019). Hukum Investasi \& Pasar Modal. Jakarta: Sinar Grafika.

\section{Jurnal}

Dourado, E., \& Brito, J. (2014). Cryptocurrency. The New Palgrave Dictionary of Economics. Online Edition. DOI: http://doi. org/10.1057/10.1057/9780230226203.3924.

Faisal, G. (2019). Legalitas Bitcoin Menurut Hukum Investasi Di Indonesia. (Doctoral Dissertation, Universitas Pasundan.

Jumiadi, D.A.A.N.J. dan Markeling, I.K. (2018). Perlindungan Hukum Kegiatan Investasi Menggunakan Virtual Currency di Indonesia. Kerta Semaya. 4 (3). DOI: https://ojs.unud.ac.id/index.php/kerthasemaya/article/view/44077.

Koeswanto, E.S. dan Taufik.M (2017). Perlindungan Hukum Terhadap Investor Yang Melakukan Investasi Virtual Currency. Bogor: Program Magister Ilmu Hukum, Sekolah Pascasarjana Unversitas Djuanda, Jurnal Living Law ISSN 2087-4936 V 9 (1).

Kurniati, G. (2017). Akibat Hukum Pelanggaran Prosedur Pengadaan Barang/Jasa Pemerintah dan Perlindungan Hukum terhadap Organisasi Pengadaan Barang/Jasa Pemerintah. Jurnal Hukum POSITUM, 1(2), 311-327. DOI : https://doi.org/10.35706/positum.v1i2.854.

Nassir, M.N.M., Seputro.E.P.dan Setyaningrum.D.P. (2020). Proceeding of The Urecol, 233-237.

Nurailati, A., dan Azwari, P.C. (2018). Akuntansi Untuk Cryptocurrency.I-Finance; A Research Journal On Islamic Finance; 4 (2), DOI: https://doi.org/10.19109/ifinance.v4i2.2885.

Peraturan Badan Arbitrase Perdagangan Berjangka Nomor Per-01/BAKTI/01.2009 Tentang Peraturan Dan Cara Arbitrase.

Puspasari, S. (2020). Perlindungan Hukum bagi Investor pada Transaksi Aset Kripto dalam Bursa Berjangka Komoditi. Jurist-Diction, 3(1), 303-330.

Saputra, E. (2018). Dampak Cryptocurrency Terhadap Perekonomian Indonesia. In Seminar Nasional Royal (SENAR) 1(1), 491-496.

Saputri, D. M. (2020). Perlindungan Hukum Terhadap Pembeli lelang Dalam Pelaksanaan Lelang Eksekusi Hak Tanggungan. Pamulang Law Review, 2(1), 712., DOI: http://dx.doi.org/10.32493/palrev.v2i1.5340.

Shabrin, P. (2020). Perlindungan Hukum Bagi Investor Pada Transaksi Aset Kripto Dalam Bursa Berjangka Komoditi. Jurist-Diction. Jurnal Volume 3 No. 1, Universitas Airlangga, DOI: 10.20473/jd.v3il.17638. 
Syamsiah, N.O. (2017). Kajian Atas Cryptocurrency Sebagai Alat Pembayaran Di Indonesia. Indonesia Jornal on Networking And Security, DOI: http://dx.doi.org/10.2311/ijns.v6i1.1449

Tampi, M.M. (2017). Legal Protection for Bitcoin Investors In Indonesia: To Move Beyond The Current Exchange System. Jurnal Hukum \& Pembangunan, 47 (1), 83-99

Watung, P. (2020). Kajian Yuridis Mengenai Keberadaan Bitcoin Dalam Lingkup Transaksi Di Indonesia Ditinjau Dari Uu No. 7 Tahun 2011 Tentang Mata Uang. Lex Et Societatis, 7(10).

Wibisono, M.G. (2020). Ketidakmampuan Indonesia Dalam Memanfaatkan Bitcoin dan Crytptocurrency, Transformasi Global. 6 (1).

Yohandi, A., Trihastuti, N., \& Hartono, D. (2017). Implikasi yuridis penggunaan mata uang virtual bitcoin sebagai alat pembayaran dalam transaksi komersial (studi komparasi antara Indonesia-Singapura). Diponegoro Law Journal, 6(2).

Zaidun, M. (2008). Paradigma Baru Kebijakan Hukum Investasi Indonesia Suatu Tantangan Dan Harapan. 